\title{
Analysis of steel highway bridges by line-girder and exact calculation methods
}

\author{
F. Ulker ${ }^{l}$, R. Ince 2* $^{*}$ \\ ${ }^{l}$ General Directorate of State Hydraulic Works, Ankara, Turkey \\ ${ }^{2}$ Firat University, Engineering Faculty, Civil Engineering Department, Elazığ, Turkey
}

\begin{abstract}
A three-span steel bridge is analyzed in this research with Line-Girder and SAP2000 program. With the LineGirder method, analysis, calculations and design have been seen to be quite complex, tedious and timeconsuming, with conclusions that are uncertain. It has been demonstrated in this study that the analysis is done effectively in a short period of time by using precise calculation methods instead of this method and the appropriate results are achieved.
\end{abstract}

\section{Keywords}

Approximate methods; Bridge design; Finite calculation methods; Line-girder; Steel bridges

Received: 16 March 2018; Accepted: 23 March 2018

ISSN: 2630-5763 (online) C 2018 Golden Light Publishing ${ }^{\circledR}$ All rights reserved.

\section{Introduction}

Bridge design and bridge construction methods are quite in the world. Bridges are important structural systems in transport, trade and economic development and contribute to the well-being of the people. Bridges in the United States are designed according to the specifications published by AASHTO. In Turkey, based on the AASHTO specification in 2016, "AASHTO Bridge Design Specification (LRDF-2010)" has been prepared [13].

It is possible to perform analysis and design of steel highway bridges by approximate and precise calculation methods. The Line-Girder method, which uses the influence lines, is an approximate method. In 2D and 3D analysis with the SAP2000 program, the exact results are achieved using the finite element technique $[4,5]$.
Most line-girder (1D) analysis programs use influence lines to create moving load envelopes (maximum of maximums). The graphical representation of the moment effect generated by the movement of a unit load on the beam is known as the influence line. Influence lines and influence surfaces are commonly used to calculate maximum and minimum force effects at a specified point on a bridge due to moving loads. The application of influence lines is limited to linear-elastic constructions. In an isostatic bridge beam, the influence line changes linearly. For these systems; the influence line is determined by unit deflections, no force is required. In statically indeterminate structures, the influence lines are usually determined by a hyperstatic analysis [4].

Influence surfaces are used in $2 \mathrm{D}$ and $3 \mathrm{D}$ precise analyzes with the SAP2000 program. The use of moving load distribution coefficients in

\footnotetext{
* Corresponding author

E-mail: rince@firat.edu.tr
} 
curvilinear and skewed bridges, generally does not provide a suitable solution with the onedimensional Line-Girder technique. In such bridge systems, it is possible to obtain more sensitive results by referring to the influence surfaces of $2 \mathrm{D}$ and 3D precise analysis programs to determine the effects of moving loads. Both the transverse and longitudinal position of the moving load is taken into account by the influence surfaces.

\section{Analysis by the line-girder method}

In this study, continuous line-girder steel bridge analysis is carried out with SAP2000 program with influence lines. When analyzing with SAP2000, it is necessary to define a lane especially for vehicle load having moving load. As the line-girder analysis is performed, only one lane is taken along the continuous beam. As the vehicle identification, not a vehicle like the HL-93, a general vehicle definition is made. The axle load of this general vehicle is taken as unit and the load of the lane is taken as zero. These loads are affected on the beam and the influence line diagrams are obtained.

The HL-93 vehicle load from AASHTO LRFD is considered as the moving load in the steel bridge system. The HL-93 vehicle load is impacted on steel bridge as "Design Truck Load" and "Design Lane Load". The design truck loads (wheel loads) are placed in spans to obtain maximum moments and are multiplied by the influence line ordinates. Also, the design lane loads are placed in the first and last spans where the positive influence line ordinates. 33\% impact factor are applied to design truck force effect. However, the impact factor is not applied to the design lane load.

To calculate the forces created by the uniform lane load, the curvilinear influence line areas are multiplied by the lane load [4]. However, the classically calculated curvilinear areas are approximate and it is caused the results to be approximate. An appropriate curve function is determined in MS-EXCEL to calculate the exact curvilinear area. Afterwards, using numerical integration techniques, the real area is calculated using this function and the maximum bending moments are obtained by multiplying by the lane load. Hence, an improvement is made in LineGirder method which is approximate analysis technique, and in a way the results are corrected.

The ordinate values of the influence line obtained with the SAP2000 program are exact results. However, the program gives the ordinate values as a default at certain points. To calculate the envelope force effects with HL-93 Design Truck, the influence lines is fitted to the curve at MSEXCEL. Thus, the default influence line ordinates calculated in the SAP2000 program are transferred to MS-EXCEL, two functions are fitted in each span, their integration and their total area are obtained. The fictional functions include 20 polynomials, and the correlation coefficient is 1 . Hence, it is said that this is a well-approach for the definitive solution. By enveloping the design truck loads and force effects created by the design lane load, the forces to be considered in design are determined. The calculation of these forces, the impact factor $\mathrm{IM}=\% 33$ given in American AASHTO LRFD Specification and the moving load distribution coefficient LLDF $=0.56$ are used.

\section{Analysis by SAP2000 and CSIBridge programs}

SAP2000 and CSiBridge which are the programs in analysis of steel bridges are the most common analysis and design programs. In these programs, $2 \mathrm{D}$ and $3 \mathrm{D}$ analyzes are performed with finite element method and exact results are achieved. After SAP2000 V14 for bridge analysis, CSiBridge program is presented as a separate module. The bridge analysis is performed successfully in both SAP2000 v14 Bridge and CSiBridge programs. The complex calculations such as Line-Girder or SAP2000 Influence line analysis have been extinguished. With bridge programs, the precise analysis is performed not only on Line-Girder bridge but also on curvilinear and skewed bridges. Moreover, these programs provide huge flexibility in the limit situations, loading combinations and calculation of moving load distribution coefficients [5-7].

In analyzing and designing in SAP2000 and CSiBridge programs, HL-93 truck from AASHTO 
LRFD Specification is taken as a vehicle load. When this truck is defined in the program, Tandem Truck (HL-93M), Single Truck (HL-93K), TwoTruck (HL-93S) and Fatigue Truck (HL-93F) are automatically defined. Also, the dynamic effect coefficient (impact factor) is included by default with a factor of $\% 33$.

\section{Steel bridge analysis with the line-girder method}

In this study, the influence lines of a three-span continuous steel bridge shown in Fig. 1 is determined by the Line-Girder analysis method in SAP2000 program. The continuous beam is analyzed with SAP2000 program, influence lines is obtained and ordinate values for unit load at each span are shown in Fig. 2.

In analysis with the Line-Girder method, the unit load was applied to the first span at $0.4 \mathrm{~L}_{1}$, to second span at $0.5 \mathrm{~L}_{2}$, in the third span to $0.4 \mathrm{~L}_{3}$ distances and the influence line ordinates for the bending moments are determined. It is necessary to mention that the influence lines obtained are curvilinear.

The ordinate values of the influence lines shown in Fig. 2 are given in Table 1 for each span. In Table 1 , it is clear that the ordinate values of the influence line do not indicate any linear change.

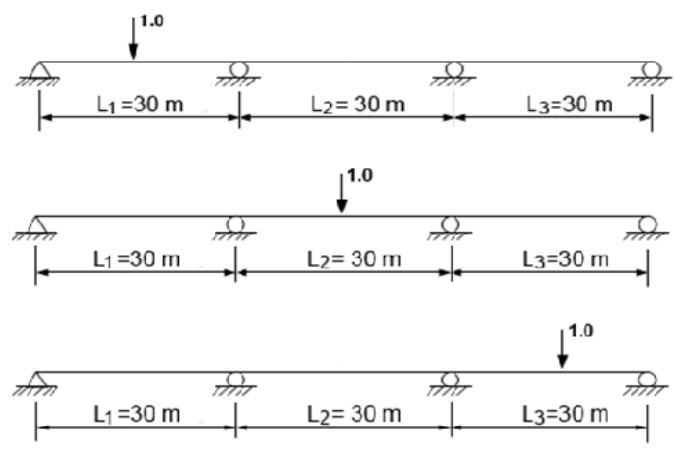

Fig. 1. Three-span steel bridge beam
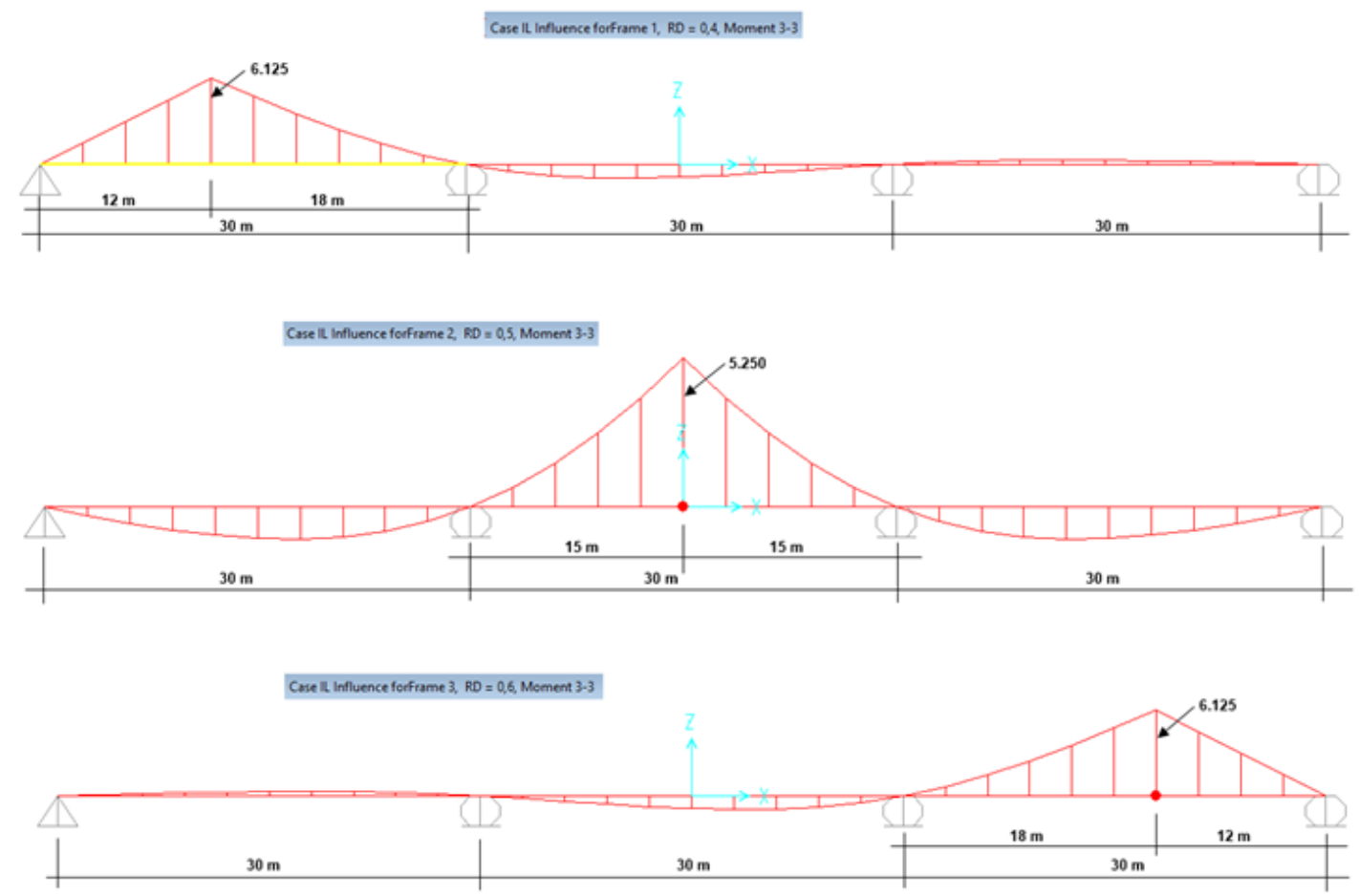

Fig. 2. Influence line ordinate values with the SAP2000 program for three-span continuous bridges 
Table 1. Continuous bridge beam ordinate values calculated by SAP2000 program

\begin{tabular}{ccccccccc}
\hline & $1^{\text {st }}$ Span & & \multicolumn{3}{c}{$2^{\text {nd }}$ Span } & \multicolumn{3}{c}{$3^{\text {rd }}$ Span } \\
\hline Station & $\begin{array}{c}\text { Station } \\
\text { Distance } \\
(\mathrm{m})\end{array}$ & $\begin{array}{c}\text { Influence } \\
\text { KN-m }\end{array}$ & Station & $\begin{array}{c}\text { Station } \\
\text { Distance } \\
(\mathrm{m})\end{array}$ & $\begin{array}{c}\text { Influence } \\
\text { KN-m }\end{array}$ & $\begin{array}{c}\text { Station } \\
\text { Sistance. } \\
(\mathrm{m})\end{array}$ & $\begin{array}{c}\text { Influence } \\
\text { KN-m }\end{array}$ \\
\hline 1 & 0.00 & 0.000 & 12 & 30.00 & 0.000 & 23 & 60.00 & 0.000 \\
2 & 3.00 & 1.484 & 13 & 33.00 & 0.690 & 24 & 63.00 & 0.653 \\
3 & 6.00 & 2.986 & 14 & 36.00 & 1.560 & 25 & 66.00 & 1.479 \\
4 & 9.00 & 4.527 & 15 & 39.00 & 2.610 & 26 & 69.00 & 2.458 \\
5 & 12.00 & 6.125 & 16 & 42.00 & 3.840 & 27 & 72.00 & 3.572 \\
6 & 15.00 & 4.801 & 17 & 45.00 & 5.250 & 28 & 75.00 & 4.801 \\
7 & 18.00 & 3.572 & 18 & 48.00 & 3.840 & 29 & 78.00 & 6.125 \\
8 & 21.00 & 2.458 & 19 & 51.00 & 2.610 & 30 & 81.00 & 4.527 \\
9 & 24.00 & 1.479 & 20 & 54.00 & 1.560 & 31 & 84.00 & 2.986 \\
10 & 27.00 & 0.653 & 21 & 57.00 & 0.690 & 32 & 87.00 & 1.484 \\
11 & 30.00 & 0.000 & 22 & 60.00 & 0.000 & 33 & 90.00 & 0.000 \\
\hline
\end{tabular}

The ordinate of the influence line is the reaction at a specific position of a unit load applied to a specific ordinate point. Therefore; while a single moving load (wheel load) is applied to that point, the magnitude of the wheel load is multiplied by the ordinate of the influence line. This process is illustrated in Fig. 3 for the AASHTO LRFD-93 design moving load. The lane load is placed in the first and third spans where the influence line ordinate was positive.

The center wheel load of the HL-93 Design truck is placed at the turning point of the influence line in the first span $\left(0.4 \mathrm{~L}_{1}=12 \mathrm{~m}\right.$ coordinate). The ordinates of the influence line are given at one-tenth point of the span. Also, SAP2000 program gives the ordinates at one-tenth point and the span divided by 10 slices. Because the front and rear axle loads of the design truck do not coincide with the ordinates of slices, two functions are determined in MSEXCEL for the influence line.

The following function can be written for the left side of the first span line of influence:

$$
f\left(x_{1}\right)=0.0021 x^{2}+0.4843 x+0.0039
$$

The following function can also be written for the right side of the first span effect line:

$$
f\left(x_{2}\right)=0.0075 x^{2}+0.2081 x-0.0193
$$

In Eqs. (1) and (2), the correlation coefficient is 1.
The front wheel ordinate value is calculated from $f\left(x_{1}\right)$ and the rear wheel from $f\left(x_{2}\right)$. The ordinate values of front and rear wheels are calculated as in the equation 3 and 4 .

$$
\begin{aligned}
f(7.7) & =0.0021(7.7)^{2}+0.4843(7.7)+0.0039 \\
& =3.858 \\
f(13.7) & =0.0075(13.7)^{2}+0.2081(13.7)-0.0193 \\
& =4.239
\end{aligned}
$$

The area under the influence line is required to calculate the effect of the lane load. Total area with the integration of the curvilinear areas $f\left(x_{1}\right)$ and $f\left(x_{2}\right)$ of the influence line is given in Eq. (5).

$$
\begin{aligned}
I= & \int_{0}^{12}\left(0.0021 x^{2}+0.4843 x+0.0039\right) d x \\
& +\int_{0}^{18}\left(0.0075 x^{2}+0.2081 x-0.0193\right) d x \\
& =84.07 \mathrm{~m}^{2}
\end{aligned}
$$

In Line-girder bridge beams, the dynamic load factor (impact factor) is given as $\mathrm{IM}=1.33$ and applied only to vehicle (truck) load. Because the influence lines are applied to one-dimensional (1D) Line-Girder beams, transverse moving load effects is calculated by applying the multi-lane moving load distribution coefficient (LLDF). According to AASHTO-LRFD 4.6.3.1, the coefficient of LLDF 
$=0.56$ is given for Line-Girder and one-loaded lane. Thus, the positive moving load moment at $0.4 \mathrm{~L}_{1}=12 \mathrm{~m}$ due to the HL-93 load is calculated in Eq. (6). As a result, the positive moving load moment in the first clearance is obtained in Eq. (7) as

In Line-girder bridge beams, the dynamic load factor (impact factor) is given as $\mathrm{IM}=1.33$ and applied only to vehicle (truck) load. Because the influence lines are applied to one-dimensional (1D) Line-Girder beams, transverse moving load effects is calculated by applying the multi-lane moving load distribution coefficient (LLDF). According to AASHTO-LRFD 4.6.3.1, the coefficient of LLDF $=0.56$ is given for Line-Girder and one-loaded lane. Thus, the positive moving load moment at $0.4 \mathrm{~L}_{1}=12 \mathrm{~m}$ due to the HL-93 load is calculated in Eq. (6). As a result, the positive moving load moment in the first clearance is obtained in Eq. (7) as
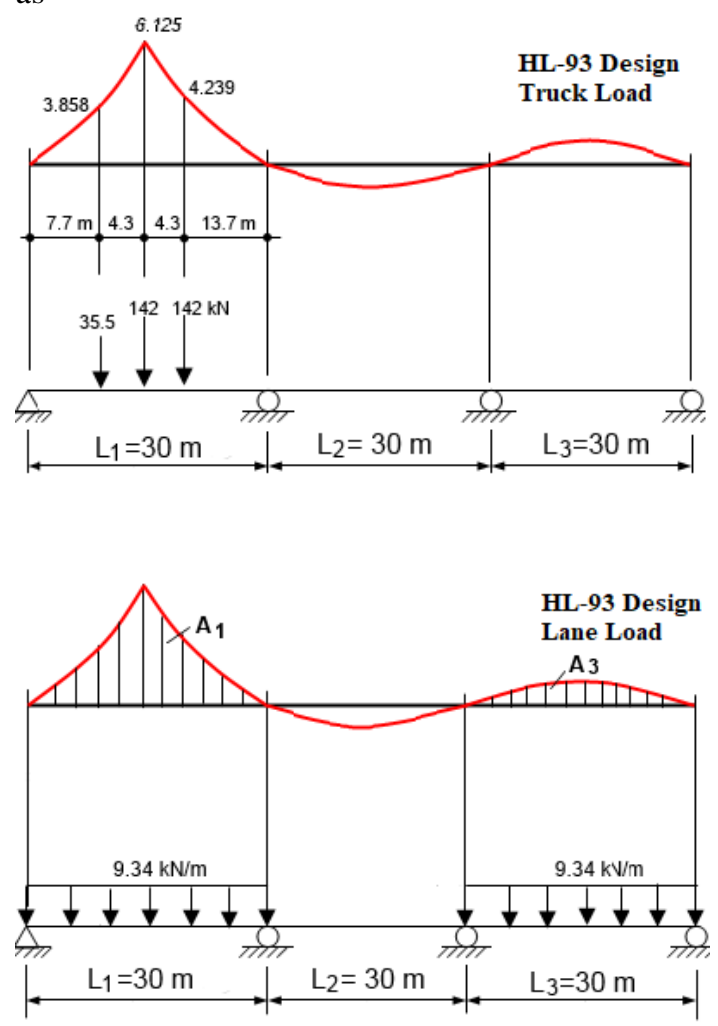

Fig. 3. Application of HL-93 moving load to influence line at $0.4 \mathrm{~L}_{1}$ distance

$$
\begin{aligned}
M= & (\mathrm{LLDF})(\mathrm{IM})[\Sigma(\text { Axle Load })(\text { Ordinate })] \\
& +(\mathrm{LLDF})[(\text { Uniform Load })(\text { Area })] \\
M= & (0.56)(1.33)[35.5 \times 3.858+142 \times 6.125 \\
& +142 \times 4.239]+(0.56)[(9.34)(84.07)] \\
= & 1638 \mathrm{kNm}
\end{aligned}
$$

\section{Steel bridge analysis with SAP2000 bridge program}

In this section; the resolution of three-span steel bridge, which is solved by the Line-Girder method above, is analyzed with the "Bridge Wizard" available in SAP2000 V14.2.

In SAP2000 Bridge program; first, a bridge with three spans $3 \times 30=90 \mathrm{~m}$ in length is defined under "Quick Bridge" as default. Because the bridge is linear form, the length of the Layout Lines is $90 \mathrm{~m}$. On this default bridge, there are 4 steel beams of which 2 exterior ones and 2 interior ones. In the bridge, two road lanes, named Lane1 and Lane2, are assigned by default. The three-span steel bridge modeled is given in Fig. 4.

Standard HL-93M, HL-93K and HL-93S vehicles are assigned as vehicles in the Bridge Wizard window. In the solution with Line-Girder method, the positive moving load moment $\mathrm{M}=$ $1638 \mathrm{kNm}$ for "HL-93K + Lane Load" in the first span is calculated.

In SAP2000 Bridge solution, as shown in Fig. 5, for this span HL-93K vehicle load on the interior beam positive moving load moment on the beam is obtained as $\mathrm{M}=1386.12 \mathrm{kNm}$. A vehicle class of HL-93MKS is defined for the combination of HL93M, HL-93K and HL-93S loads, and the Envelope Max value is again found to be $\mathrm{M}=1386.12 \mathrm{kNm}$.

The obtained $\mathrm{M}=1386.12 \mathrm{kNm}$ is a definite result from the $3 \mathrm{D}$ solution of the steel composite bridge. Moreover, the limit conditions and loading combinations are not taken into account because no bridge design is made. Compared to SAP2000 Bridge results with the Line-Girder method, it is understood that the Line-Girder Moment is $15 \%$ higher. 


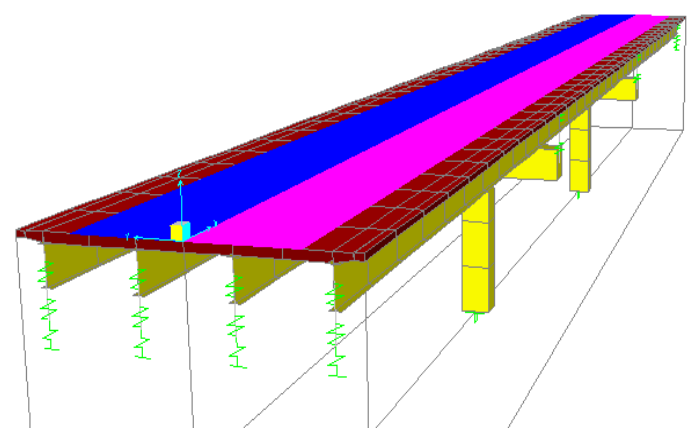

Fig. 4. Modeling of three span continuous bridge beam with SAP2000 bridge wizard

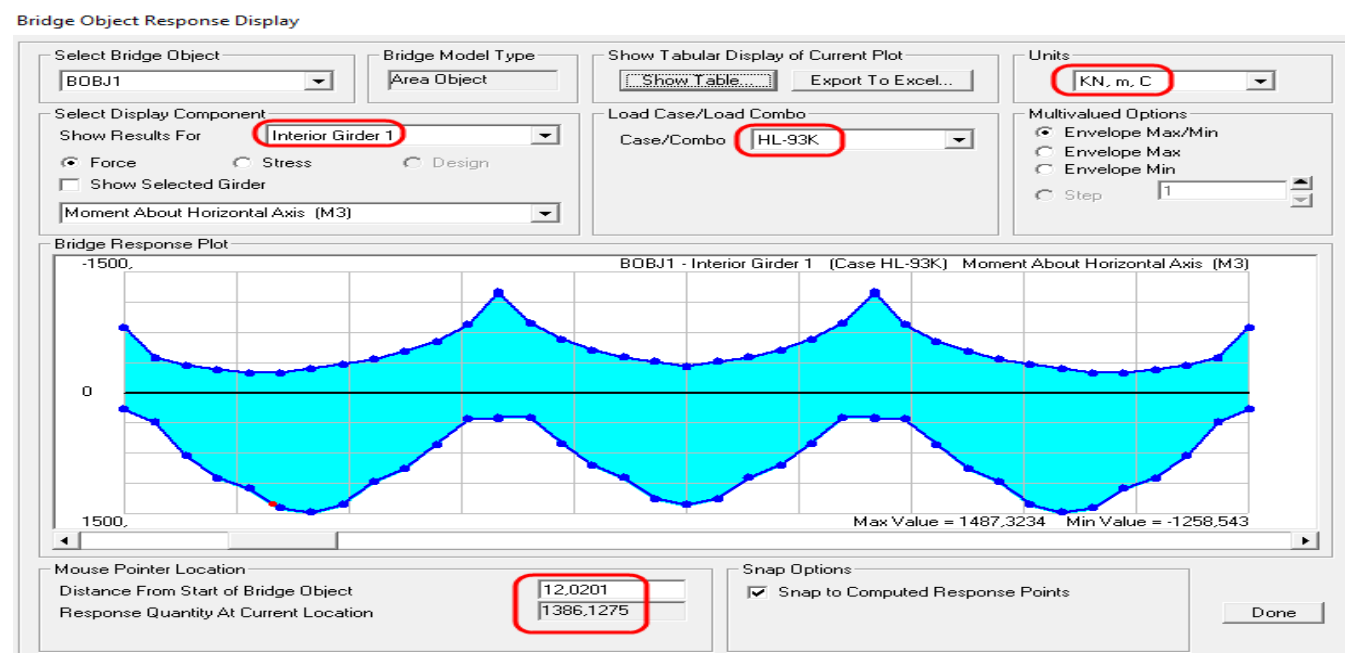

Fig. 5. Moving load moment of HL-93K vehicle loading calculated with SAP2000 bridge program

\section{Conclusions}

In this study, a three-span steel bridge was analyzed with Line-Girder and SAP2000 Bridge packet programs. Conventional Line-Girder or Beam-Line beam analysis methods used in bridge analysis and design are approximate methods and are still used in many countries.

Analysis, design and calculation using LineGirder method was shown in the above calculations, which were quite complex, tedious and time consuming. The analysis results of this method were in conclusive and approximate, the error rate was up to $25 \%$. With SAP2000 Bridge, $3 \mathrm{D}$ analysis was done by using finite element method to reach the final results in a short time.
Hence, it is understood that realistic results are achieved using SAP2000 Bridge or similar software including AASHTO-LRFD Specification in the analysis and design of bridges from now on.

\section{References}

[1] Chen W, Duan L (1999) CRC Press, Bridge Engineering Handbook.

[2] AASHTO 2010. AASHTO LRFD Bridge Construction Specifications, Third Edition with Interims, American Association of State Highway and Transportation Officials, Washington.

[3] AASHTO LRFD Bridge Design Specifications, The University of Cincinnati, James A. S. and Richard A. M., 4th Ed., July 2007. 
[4] Four LRFD Design Examples of Steel Highway Bridges, Vol. II, Chapter 1A Highway Structures Design Handbook, Published by AISI in cooperation with HDR Engineering, Inc.

[5] SAP 2000-V14.2-V15.1-V18.0, Structural Analysis Program, Computers and Structures Inc.
[6] CSiBridge V15-V16-V17, Integrated 3-D Bridge Analysis, Design and Rating, Computers and Structures Inc.

[7] Caltrans, Bridge design specifications, LFD Version, April 2000, California Department of Transportation, Sacramento, CA, 2000. 